\title{
Editorial (ERPP Issue 9.1)
}

\author{
Oon-Seng Tan
}

Received: 21 January 2010 / Accepted: 22 January 2010 / Published online: 6 February 2010

(C) Springer Science+Business Media B.V. 2010

Welcome to the first issue of ERPP for the year 2010. In this issue, we will explore several educational issues from the perspectives of policy and practice, and from Asia-Pacific countries/economies of Hong Kong, Philippines, Singapore, and Australia.

The article by Bryant and Carless discusses whether peer assessment in Hong Kong is empowering, boring, or merely facilitating examination preparation. According to the authors, current literature suggests that peer assessment contributes to the development of student learning and promotes ownership of assessment processes. These claims emerge from research conducted primarily in Western contexts. This exploratory article reports on the perspectives that a class of Hong Kong primary school students and their teachers have on their engagement with peer assessment. Through a 2-year study, the authors found that student perceptions about the usefulness of peer assessment followed from their perspectives on quality of peer feedback, peer language proficiency, and the novelty or repetitiveness of its processes. Teachers and students also viewed peer assessment as assuming a wider role in preparing for examinations and future secondary schooling. A key implication is because assessment practices are deeply cultural, in test-dominated settings, peer assessment may have the most potential when it is explicitly linked to preparation for summative assessment.

The article by Fung and Yip examines the policies of reintroducing Liberal Studies into Hong Kong secondary schools and evaluates the predicted effectiveness of the proposed curriculum. Using Ball (1992)'s "policy cycle" as a theoretical foundation, approximately 200 newspaper articles and 30 government documents were collected to identify the issues in the process of policy-making. The documentary inquiry showed that "Public Recognition", "Learning Objectives" and "Curriculum Structure" were the three major issues surrounding the reintroduction. The authors found little evidence of any "explicit" political influence related to the government of the People's Republic of China (PRC) is demonstrated. According to the research results, there were diversified opinions of the Liberal Studies curriculum. While scholars and teachers disapproved of it, parents showed appreciation. There was also

O.-S. Tan $(\bowtie)$

Nanyang Technological University, Singapore, Singapore

e-mail: oonseng.tan@nie.edu.sg 
a sharp contrast between the beliefs of the teachers and the expectations of the students with regard to Liberal Studies.

In the article by Toledano and Lapinid, using a case of Jaime Hilario Integrated School (JHIS), a Lasallian co-educational primary school located in Sitio Look, Bagac, Bataan, Philippines, the authors argue that a commonly neglected dimension in service-learning pedagogy is the consideration of community perspectives in developing these service learning projects. The authors make five suggestions for successful service learning projects in the Philippines. First, it is important for educational institutions to ensure that service-learning projects meet the needs of the community. Second, various sectors in the community have unique needs to be addressed. Third, aside from the common economic, education, and social services problems, rural poor communities also need trainings on values formation and personal development. Fourth, it is necessary that community members be involved in the initial planning and development of service learning projects. Finally, there is a need for clear explanation of the goals of service-learning projects to strengthen the relationship between service providers and recipients.

In the article by Chew and Andrews, the authors examine the role of the principal in enabling teacher leadership for pedagogical innovations and school improvement, studied in two schools in Singapore and Australia over a 3-year period. Both case study schools used the Innovative Designs for Enhancing Achievements in Schools (IDEAS) school improvement programme which originates from the Leadership Research Institute, University of Southern Queensland. The cases trace the facilitation of the IDEAS process in each school and highlight the centrality of teacher leadership in bringing about change in school-wide pedagogy and a process of school re-culturing. The research suggests that principals need to support the enabling of leadership among teachers by giving them the space, time, and responsibility to make decisions about curriculum work and ensuring that these are aligned with new organizational structures and processes. The article also discusses how the schools were different between the two countries, Singapore, and Australia, with regard to the nature of the enabling process for organizational revitalization and school capacity building.

In every issue of the ERPP, we hope that the articles will generate further discussions and collaborations among educators and researchers so that good educational philosophies and practices may be shared globally. We look forward to your valuable contributions to the ERPP. 